\title{
EN PRIMERA PERSONA (DEL PLURAL): CARRÈRE, FLAUBERT Y LA ESCRITURA SAGRADA
}

\author{
IN THE FIRST PERSON (PLURAL): \\ CARRÈRE, FLAUBERT AND SACRED WRITING
}

\author{
Francisco González Fernández \\ Universidad de Oviedo
}

\section{ABSTRACT}

With the publication of L'Adversaire, Emmanuele Carrère's work takes a decisive shift; he leaves behind the genre of the novel and, at the same time, gives up the impersonal style that is characteristic of Flaubert. By means of controlled fictions and making use of a «method's I», in Le Royaume he succeeds in taking literature to its most inquisitive expression. The inquiry into the origins of Christianity is also a fictitious, though plausible, portrayal of Luke the Evangelist as a writer and, consequently, a narrative study. Carrère interrogates the unusual «us» in the Acts of the Apostles, which is indirectly linked to the famous «us in Madame Bovary. From the analysis if these three works we can infer that the influence of Flaubert continues to be profound and that Carrère shares with him a conception of literature in which the sacred and the profane are intermingled.

Key words: Me; Us, Fiction; Bible; Inquisitive literature. 


\section{RESUMEN}

Con L'Adversaire, Emmanuel Carrère da un giro radical a su obra; al tiempo que abandona el género novelesco, renuncia al estilo impersonal flaubertiano. Mediante ficciones controladas y valiéndose de un «yo de método», logra llevar en Le Royaume la literatura inquisitiva a su máxima expresión. Esta indagación sobre los orígenes del cristianismo es también un retrato ficticio pero plausible de Lucas el evangelista como escritor y en consecuencia un estudio narrativo. Carrère se interroga acerca del extraño «nosotros» de los Hechos de los Apóstoles vinculado indirectamente con el famoso «nosotros» de Madame Bovary. Del análisis de estas tres obras se desprende que la impronta de Gustave Flaubert ha seguido siendo profunda y que Carrère comparte con él una concepción de la literatura donde se mezclan lo sacro y lo profano.

Palabras clave: Yo; Nosotros; Ficción; Biblia; Literatura inquisitiva.

Fecha de recepción: 11 de octubre de 2021.

Fecha de aceptación: 14 de diciembre de 2021.

Cómo citar: González Fernández, Francisco (2021): «En primera persona (del plural): Carrére, Flaubert y la escritura sagrada», en Actio Nova: Revista de Teoría de la Literatura y Literatura Comparada, 5: 388-416.

DOI: https://doi.org/10.15366/actionova2021.5.016 
En el caso del arte y de la literatura que se manifiestan muy particularmente en relatos, habría que recordar que el impulso humano que los origina empezó a manifestarse espontánea e impremeditadamente en creaciones de otra naturaleza, como la magia y la religión; hace muy pocos siglos que se convirtió en una forma autónoma.

Rafael Núñez Ramos (2010: 193)

La literatura de Emmanuel Carrère transita entre dos polos en cuyo punto intermedio coinciden todos los críticos en situar L'Adversaire (2000). Con la contundencia del trágico suceso que narran sus páginas, este relato escrito sobre el filo de la verdad y de la mentira separa el conjunto de su obra en dos periodos, al igual que la fecha emblemática de su publicación. En un primer momento, desde los años ochenta, escribe Carrère novelas como L'amie du Jaguar, Bravoure o La moustache en las que los ensimismados protagonistas se debaten en vano dentro de una trama laberíntica que es signo de su propia confusión mental. Inspiradas en los universos tortuosos de Lovecraft y Philip K. Dick, en materia de estilo y arquitectura narrativa estas ficciones están en cambio más en deuda con Nabokov, Perec y Flaubert.

Confesaba Carrère en 1997 que durante años la presencia invasiva de la voz de Balzac en sus novelas había vuelto para él insufrible su lectura, pero que en ese momento concreto eran «les écrivains distingués d'obédience flaubertienne, leur obsession d'impersonnalité, de perfection formelle, de livres ne tenant que par la seule puissance du style», los que le parecían sin encanto y vulgares (2016: 120). A punto de bascular hacia una escritura en primera persona, pero atento más que nunca al misterio que le ofrecen las vidas ajenas, Carrère rechaza aquello que con más fuerza y tiempo había estado abrazando.

Un día, a punto ya de terminar de escribir Hors d'atteinte?, cae en sus manos un ensayo que abre fuego sobre la posteridad de Flaubert, sobre los novelistas seguidores del dogma de la impasibilidad. Carrère acepta de buen grado los argumentos del crítico, hasta que se da cuenta de que irónicamente «ces choses si justes nous visaient, moi et le livre que je tâchais laborieusement d'écrire, décalqué de Madame Bovary pour me prouver que j'étais, et on allait voir ce qu'on allait voir, un "vrai romancier".» (2016: 363) En realidad, muy pocos apreciaron entonces su talento, pues Hors d'atteinte? (1988) fue un fiasco y a día de hoy la novela por la que siente menos afecto. Pero esta historia de una mujer moderna y algo presuntuosa que, para intentar evadirse de la vulgaridad estadística de su existencia, se 
sumerge en la espiral de los casinos en busca de una fastuosidad cosmopolita ilusoria, por caduca, al menos ayudó a su autor a entender que él también había llegado a un callejón sin salida como novelista. Sin embargo, el abandono de esta poética impersonal y objetiva sólo se consumaría a finales de la década siguiente al intentar hallar el tono adecuado para relatar el caso Romand en L'Adversaire.

La investigación que Carrère llevó a cabo durante años sobre este terrible suceso, hasta el extremo de entrevistarse asiduamente en la cárcel con Jean-Claude Romand, el embaucador y asesino confeso de toda su familia, había colocado al novelista en una posición similar a la de Truman Capote cuando escribía $A$ sangre fría. Durante sus pesquisas, Carrère leyó esta novela fundadora al menos una vez al año, cada vez más impresionado por la limpidez de su prosa cristalina y con el firme propósito de imitar su enfoque deliberadamente impersonal, hasta que reparó en que esta obra maestra de «non fiction novel» descansaba en realidad sobre un subterfugio: «Capote aimait Flaubert par-dessus tout. Il avait fait sien le vœu d'écrire un livre où l'auteur soit, comme Dieu, partout et nulle part, et il a accompli le tour de force de gommer entièrement de l'histoire qu'il racontait son encombrante présence à lui, Capote» (Carrère, 2016: 270). Pero al borrarse del relato, a pesar de la relación crucial que había mantenido con los asesinos durante los cinco años que pasaron en prisión, a pesar pues de haber formado parte de esta historia, el novelista estadounidense había faltado a su credo literario de ser escrupulosamente fiel a la verdad de los hechos.

Sin embargo, esta constatación no ayudó inmediatamente a Carrère a salir del atolladero en el que él mismo se había metido. Para relatar su novela verídica estaba tratando sin éxito de imitar a Capote, quien a su vez había imitado con éxito a Flaubert, a quien él mismo llevaba años imitando con éxito desigual. Sepultado bajo esta losa de modelos ilustres, el novelista francés seguía a oscuras, como paralizado y sin capacidad para buscar una salida. Su obstinación en querer copiar la impersonalidad de $A$ sangre fría le impedía contemplar cualquier otra solución y, como él mismo reconocería años más tarde, ni siquiera creía haber llegado en algún momento a plantearse conscientemente apostar por el uso de la primera persona. La solución llegó cuando ya no la esperaba, tras renunciar a escribir este libro que había terminado sumiéndole en la más completa depresión. Con cierto alivio por haberse librado de este proyecto infernal, quiso no obstante pasar a limpio para uso personal la experiencia vivida durante este tiempo. Con despreocupación, escribió entonces una primera frase, en primera persona: «Le matin du samedi 9 janvier 1993, pendant que Jean-Claude Romand tuait sa femme et ses enfants, j'assistais avec les miens à une réunion pédagogique 
à l'école de Gabriel, notre fils aîné. Il avait cinq ans, l'âge d'Antoine Romand.» En apariencia anodina, pero inquietante en su gélido equilibrio, esta frase contenía, sin que Carrère lo supiera aún, el germen del relato al que creía haber renunciado:

J'ai continué ainsi et c'est seulement au bout de quelques pages que j'ai compris que j'avais enfin commencé à écrire le livre qui m'échappait depuis si longtemps. En consentant à la permière personne, à occuper ma place et nulle autre, c'est-àdire à me défaire du modèle Capote, j’avais trouvé la première phrase et le reste est venu, je ne dirais pas facilement, mais d'un trait et comme allant de soi. (2016: 271-272)

En el principio era el yo... y el otro. Hay algo muy perturbador en el íncipit de L'Adversaire, en esa sucesión de frases esculpidas en un único párrafo, en ese balanceo sostenido entre las espantosas acciones de Romand y las actividades simultáneas de Carrère como padre y escritor, como si la pluma de éste amenazara con convertirse en un arma, como si se nos anunciara desde el principio que escribir semejante historia pudiera ser también, según reza la última frase del libro, un crimen o una plegaria. Fue justamente en esta suerte de prólogo, manifiesto literario y a la vez exposición insensata de una entrega total, donde descubrió Paul Otchakovsky-Laurens, su editor, la verdadera naturaleza de la escritura de Carrère: «Même si tout reste à raconter, tout est dit là du coeur secret du livre et de son absolue nécessité. En trois phrases dont la construction, l'assemblage et le sens qui ne s'en détache jamais me laissèrent comme devant quelque chose de sacré, je m'en souviens très précisément, stupéfait et même terrorisé.» (2018: 201) En el íncipit de este libro, bello comienzo de lo terrible, todo respira la conversión literaria que se cumple a través de sus páginas. En 2017, en el discurso de recepción del premio FIL, explicaba Carrère que este abandono del enfoque impersonal y la plena asunción de la primera persona tuvo para él una trascendencia sin igual: «Je pense sans exagérer que ce choix m’a sauvé la vie.» (2018a: 536) $\mathrm{Y}$ es que el cambio de perspectiva narrativa viene acompañado de una transformación personal, toda vez que la plena aceptación del «yo» impulsa al novelista hacia los demás, le expulsa paradójicamente de la prisión egotista que había levantado a su alrededor, pasando del discurso algo enfático de sus novelas iniciales al discurso empático del resto de su producción. Una conversión literaria que hace eco a otra religiosa, a la que sigue tres años después una reconversión, y que constituyen ambas el motor de Le Royaume, el libro inclasificable en el que se cumple la poética de Carrère.

Después de años empeñado en construir cárceles imaginarias donde ubicar a sus atormentados personajes, habla Carrère por fin en primera persona, no necesariamente, 
como suele pensarse, para dar rienda suelta al espectáculo de su intimidad, sino como una forma de abrirse al otro. Su obra desde entonces es una exhibición del Yo, pero sólo en la medida en que gracias a la primera persona tiende hacia los demás, hacia un Nosotros. Para encontrar su voz, Carrère ha tenido que renunciar a seguir los pasos de Flaubert y de sus discípulos, aunque, como veremos, esto no signifique que haya abjurado del solitario de Croisset, mártir de la frase y santo patrón de los escritores modernos. Tampoco ha abandonado del todo la ficción, pues, como él mismo explica en una entrevista, a pesar de no escribir ya novelas recurre en sus obras a «toutes les techniques, toutes les ressources du roman, absolument sans scrupules et en le revendiquant», pues, aunque lo que escribe no sea una novela, «c'est écrit comme un roman.» (Demanze \& Carrère,2014: 15) Con Jean-Claude Romand se despide Carrère de la novela, del roman, pero no así de la ficción. Pues, aunque su material no sea ya imaginario, sus relatos no prescinden por ello del componente ficticio, al que otorga de hecho una función heurística que debería ser propia de una investigación social.

Por azares del mundo editorial, el año 2014 en que Emmanuel Carrère publicaba Le Royaume, el historiador y escritor Ivan Jablonka daba a conocer también en Francia un ensayo que podría perfectamente leerse como un comentario de este libro sobre los primeros tiempos del cristianismo. Aunque también se podría a la inversa considerar a este último como una acabada ilustración de las ideas expuestas en L'bistoire est une littérature contemporaine. Como sugiere ya su título, el propósito del ensayo de Jablonka era (hacer) reflexionar sobre los beneficios que podría reportar a la investigación histórica asumir una escritura más libre, propia de la literatura, habitual antes de que se impusiera el cientificismo histórico, la objetividad y la impersonalidad resumida en el ineludible «nosotros» mayestático.

Este manifiesto por las ciencias sociales es asimismo una descripción de esa literatura que se afana por agarrarse a lo real y en la que Jablonka reconoce tanto un síntoma como un posible modelo para los estudios históricos. Aunque $A$ sangre fría no fue la primera non fiction novel, este término se popularizó gracias al éxito de la obra de Capote, pero desde entonces designa tal variedad de obras que más parece cajón de sastre que etiqueta operativa. En realidad, como evidencia Jablonka, esta literatura -cuya aparición en torno a 1960 constituye «la deuxième révolution littéraire $\mathrm{du} \mathrm{xx}^{\mathrm{e}}$ siècle, après celle du roman moderne» (Jablonka,2014: 251) - se caracteriza menos por ocuparse de lo real -no otra pretensión tenían ya la novela realista y la naturalista- que por ser la investigación expresa de un individuo en busca de la verdad. Tales historias lo son en el mismo sentido que la Historia de 
Heródoto -obra fundadora y paradigma del género, en opinión de Jablonka-, es decir, investigaciones o, como prefiere traducir Kapuściński, (2006: 89), «inquisiciones». Por ello, sería más ajustado a la naturaleza de estas obras hablar de «literatura inquisitiva», de la que L'Adversaire de Emmanuel Carrère, Soldados de Salamina de Javier Cercas, Rien ne s'oppose à la nuit de Delphine de Vigan y Laëtitia ou la fin des hommes de Ivan Jablonka -predicando con el ejemplo- son textos representativos. Lo que distingue a estas obras no es tanto su renuncia a la fabulación para poder abrazar lo real como que se constituyen en una investigación esencialmente verbal. Y semejantes inquisiciones son las que movilizan el lenguaje hasta convertirlo en literatura: «l'enquête elle-même oblige à écrire, c'est-à-dire à travailler la langue, élaborer une narration, construire un texte, détraquer les habitudes. (...) La littérature, c'est la recherche» (Jablonka, 2014: 251).

Ahora bien, tales indagaciones difícilmente pueden llevarse a cabo de manera impersonal e impasible. Se trata de una literatura del «yo», pero ajena a cualquier tentación de lirismo y narcisismo, donde la primera persona del singular dota de mayor libertad al investigador-escritor; un «yo de método», como lo designa Jablonka, «pour se défaire de luimême, pour parler des autres plus objectivement», un «yo» que nos recuerde que nos somos «"moi, moi, moi”, mais "il-je” en tant que je suis construit, façonné par d'autres choses que moi, intersection de faisceaux qui s'appellent institutions, classes sociales, valeurs, principes éducatifs». Un «yo», en fin, que linda con un auténtico «nosotros»: «Ce "je” communique donc aisément avec le "nous" de l'équipe, du collectif réuni sur la base d'un projet, loin du “nous" de majesté emphatique et creux.» (Jablonka, 2014: 293) Y este «yo» debería asimismo involucrar al lector haciéndole partícipe de su investigación, desplazar «le centre de gravité de la narration et consacrer une part du récit à la recherche elle-même, c'est-à-dire la manière dont on a raisonné, enquêté, douté, prouvé.» (2014: 296) Así concibe justamente Carrère sus obras literarias en las que, como él mismo explica, se juntan a menudo la cronología «de l'histoire que je raconte et celle de sa rédaction, les deux pouvant se superposer, aller de pair ou alterner.» (2018: 16) Este es el «yo» del que se vale en Le Royaume para hacernos vivir la historia, más concretamente la de los primeros años del cristianismo, para intentar devolver plausiblemente a la vida a los hombres que protagonizaron esta historia. Y esto no parece realizable sin recurrir a algún tipo de ficción.

Por otra parte, hablar de non fiction novel no se ajusta del todo a la verdad, no sólo porque incluso alguien tan estricto y modélico como Truman Capote no dudó en inventarse diálogos en $A$ sangre fría, sino también porque el escritor inquisitivo no podría -ni el 
historiador debería- prescindir de un tipo de ficciones de enorme potencial cognitivo y comunicativo. A estas ficciones que se presentan como tal, que se alejan de lo real para volver sobre ello con mayor impacto y que, en lugar de ser lúdicas o arbitrarias, vienen guiadas por el razonamiento, Jablonka las ha bautizado con el nombre de «ficciones de método».

Cuatro son las ficciones controladas y explícitas que contempla Ivan Jablonka: 1. El extrañamiento con el que se mira al mundo o al pasado para tomar una distancia frente a lo real: así, por ejemplo, para traducir nuestra total incomprensión del arte parietal, LeroiGourhan imagina el desconcierto de un alienígena que entrara en una iglesia y observara la escultura de un ser humano clavado a dos maderos entrecruzados. 2. La plausibilidad: el historiador no sólo enuncia lo que ha sucedido, sino, especialmente cuando faltan fuentes de información, lo que ha podido suceder (lo posible) y lo que verosímilmente ha sucedido (lo plausible). La plausibilidad no es más «qu'un scénario très possible, une hypothèse non seulement moulée dans la réalité, mais tributaire d'elle et commandée para les sources dont nous disposons ; autrement dit, une fiction étayée, visible et humble.» (2014: 202) 3. Conceptos y teorías: explicaciones causales, postulados, metáforas, abstracciones, guiones del «como si», historias contra-factuales en el reino de la Ucronía, anacronismos controlados, etc. 4. Procedimientos narrativos: uso del presente histórico, objetividad, simbolismo, focalización sobre objetos, dramatización, esquemas narrativos, etc.

Estas y otras ficciones de método, a las que recurren los historiadores-escritores para entender y comunicar a sus lectores las acciones humanas, son justamente las que hacen que Le Royaume se lea como una novela. En Le détroit de Behring (1986), una esclarecedora introducción a la Ucronía, propone Carrère al lector imaginar lo que habría sucedido de no haberse dado un hecho concreto. No sólo histórico, también literario: cabe preguntarse, por ejemplo, si una obra, que es tributaria de su tiempo, del estado de la sociedad, de una tradición, sería la misma de no haberse producido alguno de los acontecimientos que la determinaron: «Flaubert, en Uchronie, aurait-il écrit Madame Bovary?», se pregunta Carrère. Es la obra misma la que revela su frágil singularidad bajo este prisma:

Si Jésus, Napoléon, Shakespeare ou François Coppée n’avaient pas existé, si seuls l'eau, les roses, l'élan amoureux, la mort et les chagrins quotidiens étaient ceux que nous connaissons -car l'uchronie, jusqu'à présent, n'a guère de prise sur eux, Villon, Rilke, Mallarmé auraient-ils écrit les mêmes vers? On devine bien que non, mais alors, lesquels? (Carrère, 1986: 99-100) 
En Ucronía, la obra efectiva invita a imaginar otras muy distintas. Es una constante en la obra de Carrère considerar un acontecimiento como la sombra de otros muchos que pudieron haber tenido lugar o como el eco de otros que ocurrieron efectivamente. En este sentido, abundan en su obra los anacronismos voluntarios, y muy especialmente en Le Royaume, donde constituyen toda una retahíla: así, por ejemplo, a pesar de ser infundado, el rumor de que Nerón había incendiado Roma crecía como el de «l'implication du FSB et de Poutine dans les terribles attentats qui ont ensanglanté Moscou en 1999.» (2014: 481) O también cuando presenta a la mujer del intendente de Herodes como una «bourgeoise ennuyée, Bovary juive, cliente idéale pour un gourou.» (2014: 380) Anacronismos como éstos tienen la función de acercar más vívidamente el pasado al lector, pero también de mostrar los hechos con una luz más auténtica, a semejanza de las escenas bíblicas donde los maestros antiguos representaban Galilea con la apariencia de la Toscana del siglo XV, razón por la cual, según argumenta Carrère, eran precisamente realistas «dans la mesure où ce qu'ils représentaient était vraiment réel. C'étaient eux, c'était le monde où ils vivaient.» (2014: 386) Por ello, aunque se haya podido criticar el (ab)uso que Carrère hace de lo anacrónico, en realidad este recurso está en perfecta consonancia con el propósito y con el espíritu de Le Royaume, con esta investigación en la que Carrère ha sabido realizar un soberbio retrato de Lucas como escritor dotándole de muchos de sus propios rasgos. Un retrato por lo tanto necesariamente anacrónico, pero plausible y tan cargado de verdad como el lienzo San Lucas pintando a la virgen en el que Rogier van der Weyden, el pintor predilecto de Carrère, se representó a sí mismo en la figura del evangelista, para gran satisfacción del escritor francés: «'imagine aussi bien van der Weyden que Luc avec ce visage allongé, sérieux, méditatif. Que le premier se soit peint sous les traits du second, cela me plaît d'autant plus que, moi-même, je fais la même chose.» (2014: 388) Le Royaume es, en efecto, también un autorretrato del artista como evangelista.

Empieza Carrère Le Royaume evocando la exitosa serie televisiva Les Revenants en la que había participado como guionista. El argumento no puede ser más sencillo: en un pueblo de montaña, regresan un día a sus hogares los muertos tal como eran en el momento de su desaparición y sin tener consciencia de lo que les ha sucedido. Serie de atmósfera realista, en las antípodas de Walking Dead, Les Revenants es toda ella una ficción de método, ya que plantea qué ocurriría y cómo reaccionaríamos si viniera a darse este hecho imposible. Cuando le hablaron del proyecto, Carrère no pudo reprimir su entusiasmo : «Je n’écris plus de fiction depuis longtemps mais je sais reconnaitre un dispositif de fiction puissant quand on m'en 
propose un, et celui-ci était de loin le plus puissant qu'on m'ait proposé dans ma carrière de scénariste.» (2014: 10) Si esta ficción le atraía tanto, y si con ella arranca Le Royaume, no es sólo por el potencial que atesoraba, sino sobre todo porque toca de lleno una cuestión que nunca ha dejado de intrigar a su autor: ¿Cómo es posible que alguien crea de verdad, como él mismo hizo en un momento de su vida, en algo imposible como la resurrección? A contestar a esta pregunta está dedicado en buena medida Le Royaume.

Carrère sostiene al comienzo del libro que al abordar un tema le gusta cogerlo como con tenazas (2014: 16). En este caso su propósito era escribir sobre las primeras comunidades cristianas y a la vez averiguar quién era aquel creyente convencido que él mismo había sido entre 1990 y 1993. En el momento de iniciar su libro, reconvertido en el cerebral escéptico de siempre, la lectura de los viejos cuadernos donde había volcado sus comentarios evangélicos le hace contemplar atónito al devoto que fue un tiempo. Siente entonces el deseo irrefrenable de volver sobre esta cuestión central «de notre histoire à tous, de mon histoire à moi. De revenir aux textes, c'est-à-dire au Nouveau Testament.» (2014: 145) Pero, ¿cómo hacerlo ? ¿Desde qué perspectiva? «Ce chemin que j’ai suivi autrefois en croyant, vais-je le suivre aujourd'hui en romancier? En historien? Je ne sais pas encore, je ne veux pas trancher, je ne pense pas que la casquette ait tellement d'importance. Disons en enquêteur.» (2014: 145-146) Pongamos, terminada la lectura del libro, como un investigador que no duda en emplear los instrumentos del historiador y del novelista, como un escritor inquisitivo.

Siendo la figura de Jesús inabordable de frente por cegadora, opta Carrère por hacerlo al sesgo, por «ouvrir l'enquête un peu en aval et commencer par lire, aussi attentivement que je peux, les lettres de saint Paul et les Actes des apôtres.» (2014:146) De hecho, a parafrasear y comentar ambos textos, a contarlos con mirada inquisitiva, está dedicada la mayoría de Le Royaume, centrándose sobre todo en la figura de Lucas, su semejante, su hermano. Y aquí radica tal vez la principal originalidad de este libro, en su aproximación al autor del tercer Evangelio y de los Hechos de los Apóstoles, que no es ni la del creyente ni la del teólogo, sino la del novelista que ha sido y en el fondo sigue siendo. Lo que Carrère pretende averiguar es de dónde sacó su ilustre colega lo que escribió : «Je suis un écrivain qui cherche à comprendre comment s'y est pris un autre écrivain, et qu'il [Lucas] invente souvent, cela me semble une évidence.» (2014 :405) Para ello imagina al evangelista, lo convierte en un ser ficticio: «car bien sûr c'est un personnage de fiction, tout ce que je soutiens c'est que cette fiction est plausible.» (2014 :466) Tal es la principal premisa que se ha marcado Carrère al escribir esta «ficción de método»: que su retrato y su historia resulten 
ya no irrefutables, pero al menos plausibles, y en este viaje en mitad de esa selva oscura que es el Nuevo Testamento le acompaña un guía de excepción, el pionero francés del estudio razonado de los textos sagrados: Ernest Renan.

Más allá del escándalo que supuso la publicación de su Vie de Jésus, que había de convertirle en una de las figuras más odiadas del siglo XIX, con éste y los seis volúmenes restantes de su Histoire des origines du christianisme logró Renan acercar la religión al terreno de la historia. Para Carrère, quien admite abiertamente que disfrutó parafraseando sus libros, lo más apasionante de Renan es la honestidad con la que cuenta la historia, «sa façon d'expliquer au lecteur comment il fait sa cuisine d'historien: de quelles sources il dispose, comment il les exploite et en vertu de quels présupposés», pero también su manera de escribir no para probar algo, «mais pour raconter ce qui s'est passé.» (2014: 182) La misma clase de honestidad con la que a su manera cuenta Carrère la historia.

Justamente, Ivan Jablonka ve en Renan a uno de los estudiosos más representativos de la concepción histórica que reivindica en su manifiesto. De entre los muchos méritos del historiador de la religión destaca su acierto al recomendar y emplear, junto a la introspección y la psicología, la imaginación "parmi les outils du biographe: pour faire revivre les âmes du passé, "une part de divination et de conjecture doit être permise" [Vie de Jésus].» (Jablonka, 2014: 85) Esta defensa de la conjetura en la investigación histórica, la expondrá Renan con mayor claridad aun en la introducción del volumen siguiente, en Les apôtres, precisamente el texto al que más se ha adherido Carrère en Le Royaume. En ese estudio argumentaba Renan que la formulación de hipótesis resulta indispensable para el historiador y es tan lícita como tratar de recomponer los frontones del Partenón. Para ello hay que apoyarse en textos antiguos, en todas las fuentes de información disponibles, pero también, y no en menor grado, inspirarse en el estilo de los inimitables fragmentos conservados:

Un tel procédé est d'autant plus légitime en histoire que le langage permet les formes dubitatives que le marbre n'admet pas. Rien n'empêche même de proposer le choix au lecteur entre diverses suppositions. La conscience de l'écrivain doit être tranquille, dès qu'il a présenté comme certain ce qui est certain, comme probable ce qui est probable, comme possible ce qui est possible. (Renan,1866: VII)

Y este es el criterio que abiertamente hace suyo Carrère para mantener el interés de su propia investigación: «si je suis libre d'inventer c'est à la condition de dire que j’invente, en marquant aussi scrupuleusement que Renan les degrés du certain, du probable, du possible 
et, juste avant le carrément exclu, du pas impossible, territoire où se déploie une grand partie de ce livre.» (2014: 485) Este teatro de las operaciones es el de lo plausible, el de las hipótesis fundadas al partir de hechos y de testimonios fehacientes, pero también, como en este caso, de la experiencia y conocimiento que atesora Carrère como escritor y que le permite ponerse en el lugar de su insigne colega y tratar así de discriminar en su relato los detalles y acontecimientos auténticos de aquellos que su talento le permitió inventar.

Si Carrère se muestra particularmente cauto a la hora de formular hipótesis históricas, en materia de escritura se siente y confiesa mucho más libre y seguro. Por ejemplo, tan convencido está de que el parentesco entre Juan Bautista y Jesús, proclamado en el tercer evangelio, es obra exclusiva de Lucas que está incluso dispuesto a jugarse su propia salvación: «ce cousinage de Jésus et de Jean, dont il n'est question nulle part ailleurs, je suis prêt à parier ma place dans le Royaume des cieux que c'est une invention (...) de Luc.» (2014: 565) De modo que a continuación imagina a Lucas sentado frente a sus cuadernos, pero, falto de ideas, incapaz de seguir escribiendo; hasta que de repente, en su cama, en las termas o paseando por el campo de Marte, se le ocurre convertirlos en primos:

Et si Jésus et Jean étaient cousins? Voilà qui arrangerait bien ses affaires de narrateur! Pour en avoir connu parfois l'équivalent, j'imagine l'excitation de Luc et j'imagine que dans le sillage de cette idée s'est déployée comme une évidence toute la composition de ses deux premiers chapitres, majestueuse et pure comme une fresque de Piero della Francesca. (2014: 565)

En realidad, todo el comienzo del tercer evangelio huele a ficción, con la salvedad del prólogo en el que Lucas declara su intención de transmitir, al igual que hicieran otros antes que él, los acontecimientos que vivieron los primeros testigos y servidores de la Palabra «entre nosotros». Al comparar estas primeras líneas con el íncipit del evangelio de Marcos y con el de la Historia de la guerra del Peloponeso de Tucídides determina Carrère que Lucas procede como un historiador o un reportero, como alguien que lleva a cabo una investigación, y en este sentido reconoce en él su propio reflejo: «mon projet à moi, c'est d'enquêter sur ce qu'a pu être cette enquête.» (2014: 328) Pero finalizado el prólogo, cuando empieza propiamente el evangelio, todo da un giro inesperado: «En tiempos de Herodes, rey de Judea, había un sacerdote llamado Zacarías, de la clase sacerdotal de Abías. Su mujer, llamada Isabel, era descendiente de Aarón.» (Lucas 1:5-7) Estamos ya en otro registro bien distinto, como si aquí diera comienzo un cuento. ¿Qué son esas primeras líneas?, se pregunta Carrère: «Un roman. Un pur roman.» (2014: 561) Y a partir de este íncipit, en el que poco 
faltaría para que viéramos en él una prefiguración de uno de los Tres cuentos religiosos de Flaubert, rastrea Carrère la parte de ficción que ha deslizado Lucas en su texto, identificándose con él hasta el mimetismo.

Pero en Le Royaume no emprende Carrère su viaje a los orígenes del cristianismo partiendo del evangelio de Lucas, sino a través de una singularidad que detecta en la otra obra que éste escribió y que en rigor tendría que leerse consecutivamente: los Hechos de los Apóstoles. Si Lucas nunca dice «yo» en su evangelio, ya que no conoció a Jesús y sólo dispone de información de segunda o tercera mano, muy distinta es su participación en lo que narra en su obra siguiente, dedicada en su mayor parte a contar la vida del apóstol de Tarso. Pero, advierte Carrère, a pesar de haber sido el compañero de Pablo, Lucas empieza y prosigue su relato de los hechos como si no hubiese estado implicado en ellos, en tercera persona («Cuando salieron de la Sinagoga...»), hasta que bien avanzada su narración algo cambia: «à un moment de cette biographie il se passe quelque chose de surprenant: on passe soudainement, sans prévenir ni expliquer pourquoi, de la troisième à la première personne». Parece poca cosa, pero Carrère tenía buenas razones para reparar en ello: «C’est un moment furtif, on pourrait ne pas le remarquer, mais quand je l'ai remarqué je suis tombé en arrêt.» (Carrère,2014: 147) Y no es para menos, porque, como hemos visto, el giro de la tercera a la primera persona ha sido crucial en su propia trayectoria como escritor. Reproduce entonces Carrère el pasaje en cuestión subrayando los «nous» que hacen su inesperada aparición:

«Une nuit, Paul eut une vision. Un Macédonien lui apparut, qui l'implorait: viens en Macédoine, viens à notre secours! Après cette vision de Paul, nous avons cherché à partir pour la Macédoine, pensant que le Seigneur nous y appelait pour annoncer la bonne nouvelle. Prenant la mer à Troas, nous avons fait voile directement vers Samothrace puis, le lendemain, débarqué à Néapolis.» (cit. en Carrère,2014 :147)

Pocas veces se había visto en verdad un cambio de rumbo semejante: durante más de la mitad del relato los acontecimientos habían sido narrados escrupulosamente en tercera persona y de repente, en el capítulo 16, sin previo aviso ni explicación alguna, surge como de la nada un narrador homodiegético, un «nosotros» como el que podríamos encontrar en una novela moderna. Pasado el asombro, se interroga Carrère sobre la naturaleza de este pronombre personal:

Qui recouvre ce «nous», ce n'est pas clair: peut-être tout un groupe, composé du narrateur et de compagnons qu'il n'estime pas assez importants pour 
les nommer. Peu importe: depuis seize chapitres, nous lisions une chronique impersonnelle des aventures de Paul, et voici que tout à coup quelqu'un surgit, qui parle. Au bout de quelques pages, ce quelqu'un s'éclipse. Il regagne les coulisses du récit, d'où il resurgira quelques chapitres plus tard pour ne plus quitter la scène jusqu'à la fin du livre. À sa manière, qui est à la fois abrupte et discrète, il nous dit ce que ne dit jamais l'évangéliste : j'étais là. Ce que je vous raconte, j'en ai été le témoin. (2014: 147)

En este pasaje descubre pues Carrère un detalle que a cualquier otro habría pasado desapercibido, pero que en su caso le interpela directamente porque conecta con su propia vivencia de escritor, porque se trata del estilo que le cautiva en la escritura de los demás y que busca para sí mismo:

J'aime, quand on me raconte une histoire, savoir qui me la raconte. C'est pour cela que j'aime les récits à la première personne, c'est pour cela que j'en écris et que je serais même incapable d'écrire quoi que ce soit autrement. Dès que quelqu'un dit «je» (mais «nous», à la rigueur, fait l'affaire), j'ai envie de le suivre, et de découvrir qui se cache derrière ce «je». J'ai compris que j'allais suivre Luc, que ce que j'allais écrire serait en grande partie une biographie de Luc, et que ces quelques lignes des Actes des apôtres étaient la porte que je cherchais pour entrer dans le Nouveau Testament. Pas la grande porte, pas celle qui ouvre sur la nef, face à l'autel, mais une petite porte, latérale, dérobée : exactement ce qu'il me fallait. (2014: 147-148)

Angosta es sin duda la puerta que introduce al Nuevo Testamento, pero Carrère era de los llamados a cruzarla. Como un «Ábrete, sésamo», este enigmático «nosotros» obra el hechizo de introducirnos en el universo literario de las sagradas escrituras, en un templo verbal majestuoso que recorreremos tras los pasos de Lucas y de la mano de Emmanuel Carrère. Desde que aparece en escena en Troas, donde presumiblemente se ha encontrado con Pablo, no dejamos ya de seguirle en cada etapa de su viaje, en cada encrucijada de su escritura, poniendo especial atención Carrère en sus idas y venidas. Porque este pronombre personal se esfuma tan inesperada y súbitamente como había surgido:

Luc disparait à cet endroit de son propre récit. Soit qu'il n'ait pas voulu suivre Paul, soit que Paul n'ait pas voulu qu'il le suive, il rentre dans la coulisse d'où il ne ressortira que trois chapitres et sept ans plus tard. Alors seulement il reviendra au «nous» du témoin oculaire, et dans les mêmes parages. (Carrère,2014: 193)

Un momento crucial, narrativamente hablando, al que Carrère dedica un largo comentario que resulta muy instructivo: 
La seconde entrée de Luc dans les Actes est aussi peu fracassante que la première. On l'a vu, sous la forme d'un «nous» énigmatique, se matérialiser aux côtés de Paul sur le port de Troas, tenir lieu de narrateur le temps d'un chapitre en Macédoine, puis s'éclipser quand Paul quitte Philippes. Sept ans s'écoulent, nous voici de nouveau sur le port de Troas. Paul y reparaît accompagné non plus de deux disciples mais d'une dizaine, délégués par les églises de Grèce et d'Asie pour porter en leur nom le produit de la collecte aux pauvres et aux saints de Jérusalem. (...) «Quant à nous, enchaîne tranquillement Luc, nous avons quitté Philippes par mer après les jours des Azymes et les avons retrouvés à Troas, où nous sommes restés sept jours avant d'embarquer.»

Difficile de se mettre moins en avant. Il n'était plus là, il est là de nouveau. On ne le remarque pas plus que la dernière fois, il n'empêche qu'à partir de cette phrase Luc reprend les rênes du récit et ne les lâchera plus jusqu’à la fin. Tout devient plus précis, vivant, détaillé : on sent qu'on a affaire à un témoin. (Carrère,2014: 276)

El narrador no puede resultar más desconcertante: aparece, desaparece y vuelve a aparecer sin previo aviso, como por encantamiento, como ese Simón el Mago al que justamente había retratado Lucas (Hechos, 8:9-24). Pero lo importante para Carrère es que la presencia de este «nosotros» vuelve más vívido y auténtico el relato, de tal modo que al leer por ejemplo que «nosotros partimos de Troas para Assos» tiene también él la gozosa sensación de estar allí: «je suis ravi, je crois y être.» (2014: 288) Tal es la magia de la literatura, que nos permite durante el tiempo de la lectura vivir vidas ajenas como si fueran las nuestras.

Este «nosotros» es la entrada por la que se introduce Carrère para pegarse a Lucas en su misión de narrador, hasta identificarse con él. Pero el escritor francés encuentra también otro acceso para adentrarse en la nave principal de este templo verbal, permitiéndole en esta ocasión asumir y justificar su parte de invención en relación al relato de Lucas. Se diría que es una entrada paralela al «nosotros» que se había esfumado sin más durante tres capítulos y siete años, ya que se trata de una elipsis narrativa no menos extraña. Como puntualiza Carrère, en cuanto reconoció esta suspensión inesperada y algo incongruente del relato, se convirtió para él en la segunda puerta por la que accede a este libro, tras la irrupción del «nosotros»:

Celle-là aussi, c'est une petite porte. Il faut être attentif, on peut passer devant sans la voir. Luc écrit : «Félix espérait que Paul lui donnerait de l'argent, aussi l'envoyait-il souvent chercher pour converser avec lui.» Puis : «Au bout de deux ans, Félix fut remplacé para un nouveau gouverneur, Porcius Festus.»

Entre ces deux phrases, les éditions modernes passent à la ligne mais on ne passait pas à la ligne dans les manuscrits antiques : ils coulaient d'un seul tenant, sans ponctuation, sans même d'espace entre les mots. Dans cette absence d'espace se logent deux années de blanc, et dans ces deux années de blanc le cœur de ce que je voudrais raconter. (2014: 325-326) 
Carrère se cuela en el hueco que Lucas le ha dejado libre. Si hasta ese momento había seguido fielmente las escasas fuentes existentes sobre los orígenes del cristianismo, entrecruzándolas y haciéndolas concordar, si cree haber cumplido su trabajo con honestidad y no engañar al lector sobre el grado de probabilidad de lo que le cuenta, para los dos años que pasó Pablo en Cesarea no tiene nada, y esto le sitúa en una nueva posición frente a su propio relato: «Je suis à la fois libre et contraint d'inventer.» (2014: 326) Y es lo que hará desplegando todo su talento.

Pero esta singular elipsis, este blanco que se ha tragado dos años enteros del relato, provoca en mí una reacción bien distinta. Este pasaje de los Hechos de los Apóstoles me trae inmediatamente a la memoria, o, mejor dicho, me lo trajo cuando leí por primera vez Le Royaume, uno de los blancos más conocidos de las letras francesas, tanto que me sorprende que Carrère no lo haya mencionado ni siquiera de pasada, pues parece poco plausible que con sus conocimientos de literatura francesa y dada la identidad y prestigio del novelista en cuestión, no lo tenga en mente. Se trata, en efecto, de la elipsis de más de quince años que Flaubert intercaló casi al final de L'Éducation sentimentale (2002: 615), un pequeño hueco entre el capítulo quinto y el sexto de la tercera parte, que empieza con el emblemático «Il voyagea», por donde se abisma todo el Segundo Imperio.

Proust fue sin duda quien más contribuyó a la popularización de este famoso blanco. En su encendida defensa del estilo de Flaubert, el autor de En busca del tiempo perdido puso incluso esta elipsis por encima de los muchos méritos que tenía el novelista. Como él mismo reconocía, este pasaje -que se complacía en reproducir y analizar- le conmovía porque en él había visto la consecución de sus propias investigaciones sobre el tiempo y porque nada le parecía más hermoso en toda la novela de Flaubert: «À mon avis la chose la plus belle de L'Education sentimentale, ce n'est pas une phrase, mais un blanc. (...) Ici un "blanc", un énorme "blanc" et, sans l'ombre d'une transition, soudain la mesure du temps devenant au lieu de quarts d'heure, des années, des décades» (Proust, 1987: 79). Un blanco que es como la esencia del tiempo, un poco de tiempo en estado puro como el que anhelaba el propio Proust en su Recherche.

Así pues, resulta poco probable que un amante de la obra de Flaubert no haya reparado o siquiera oído hablar de esta elipsis de L'Éducation sentimentale, como improbable parece que desconozca el famoso «nosotros» del íncipit de Madame Bovary, especialmente si es alguien que presta tanta atención como Carrère al «nosotros» de Lucas, que tanto se le 
parece. Cuando leí por primera vez Le Royaume, al poco tiempo de su publicación, cada vez que su autor se demoraba en contar los avatares del «nosotros» de los Hechos de los Apóstoles, me venía inevitablemente a la cabeza el comienzo de Madame Bovary. Y digo inevitablemente, ya en abierta primera persona del singular, adoptando el «yo de método» que reclamaba Jablonka para las investigaciones en ciencias humanas, porque este «nosotros» me concierne en particular, porque forma parte de mi propia historia, de mi carrera, ya que hace ya muchos años dediqué un largo ensayo a tratar de desentrañar los misterios y las implicaciones que encerraba este «nosotros» con el que comienza la inmortal historia de Emma Bovary. Así que a medida que avanzaba en la lectura de Le Royaume esperaba el momento en que Emmanuel Carrère establecería algún tipo de analogía entre ambos insólitos narradores. Pero ese momento no llegó, pues el escritor francés nada dice en su libro al respecto.

Lástima, me dije, pues de esa comparación podría haber salido algo interesante, pero ya se sabe que la realidad no suele amoldarse a nuestros deseos. Y, aunque tenía una vaga sensación de que aquí radicaba la clave de un problema que antaño no había logrado resolver, no quise dar más vueltas al asunto y pasé página. Al fin y al cabo, todo aquello era ya muy antiguo y me ocupaba ahora de cosas bien distintas. Hasta que unos años más tarde cayó en mis manos un libro colectivo dedicado a Emmanuel Carrère que incluía abundante material inédito del escritor. Me puse a hojear despreocupadamente el grueso volumen y fue entonces cuando atrajo mi atención el título de un texto firmado por Carrère: «La première personne». Lo primero que pensé fue que en estas páginas justificaba seguramente el escritor una vez más su uso del «yo», pero me equivocaba por completo, como descubrí entusiasmado nada más leer su nota aclaratoria:

Cette petite digression sur l'étrange «nous» qui apparaît au début de Madame Bovary, puis disparaît sans retour, c'est une chute $d u$ Royaume: un de ces morceaux qu'on aime bien, qu'on aimerait bien garder, mais qui finalement passent à la trappe. Heureusement qu'ily a ce recueil pour leur donner une seconde chance. (Carrère,2018b: 440).

Ahora, cuando menos me lo esperaba, averiguaba que Carrère conocía efectivamente el curioso uso que había hecho Flaubert del «nous» al comienzo de Madame Bovary y que durante un tiempo había fantaseado incluso con la idea de compararlo con el «nosotros» de Lucas. Algo que no habría desentonado demasiado con los frecuentes anacronismos de su relato, como el de la mujer del intendente de Herodes convertida en una 
«Bovary judía». Todo corte deja algún rastro, y la obsesiva observancia con la que Carrère ha seguido las andanzas del «nosotros» apostólico y la relevancia que ha concedido al «blanco», aparecen al lector, al menos al lector que soy, como la huella de lo que fue omitido. Sólo a regañadientes había sacrificado el escritor esta digresión donde se sugería cierta afinidad entre un texto sagrado y otro profano separados por casi dos milenios. Y ahora le brindaban al escritor la oportunidad de resucitar este pasaje.

Esta digresión cercenada, cuya importancia para la comprensión de la poética de Carrère ha señalado con acierto Patricia Martínez (2019: 48), empieza con una somera constatación de la singular aparición del «nosotros» de los Hechos de los Apóstoles y de la sorpresa que le causó a Carrère advertir este paso inesperado de la tercera a la primera persona. Hasta aquí sólo se trata de un embrión de lo que acabaría desarrollando en la versión final de Le Royaume, pero Carrère no tarda en traer a colación otro «nosotros» que siempre había despertado su curiosidad:

Ce nous m'en a rappelé un autre, qui m'a toujours intrigué, c'est celui du début de Madame Bovary. Première phrase du roman: « Nous étions à l'étude, quand le Proviseur entra, suivi d'un nouveau habillé en bourgeois et d'un garçon de classe qui portait un grand pupitre.» (2018b: 441).

Tardaremos varias páginas en averiguar que este «nouveau» se llama Charles Bovary y otras treinta en verle casarse con Emma Rouault, la verdadera protagonista. Pero lo que intriga a Carrère, y a cualquier lector atento, es la misteriosa identidad de quien presenta al novato: «Qui est ce nous qui se tient au seuil du livre ?» Podría tratarse de un compañero de clase, al que habría recurrido Flaubert para autentificar su relato, pero el problema es que este testigo ocular se desvanece al concluir la primera escena sin decir nada:

Ce qui est étrange, dans Madame Bovary, c'est que ce narrateur tient son rôle dans les premières pages et ensuite disparaît complètement. (...) à partir du second chapitre, le narrateur cède la place à Flaubert, c'est-à-dire à personne. Ce qu'on lit ne nous est plus raconté par un personnage, mais par l'auteur lui-même, et pas un auteur qui met son point d'honneur à être aussi invisible dans son livre que Dieu dans sa création.Techniquement et sans doute philosophiquement, c'est une autre option, mais le plus surprenant dans le cas de Madame Bovary n'est pas ce changement de cap : c'est le fait que Flaubert n'ait pas récrit le premier chapitre pour l'harmoniser avec ceux qui le suivent. Il n'était pas si difficile de supprimer ces quelques nous devenus caducs. (2018b: 441-442) 
Al no hacerlo dejó al comienzo de Madame Bovary una anomalía que vuelve problemática toda la narración. Frente al «nous», sólo caben entonces dos explicaciones: o se trata de un artificio o de un gazapo:

Quand on se demande pourquoi il ne l'a pas fait, deux solutions se présentent : la négligence et l'intention. La première est a priori exclue de la part de l'auteur le plus obsessionnel qui ait jamais existé, capable de relire cent fois le même paragraphe pour éliminer une répétition et que cela rendait malade, à cause, de la cascade de génitifs, d'écrire : « une couronne de fleurs d'oranger » (si on ne veut pas l'écrire, à vrai dire, la seule solution est de ne pas parler de couronnes de fleurs d'oranger). D'un autre côté, si Flaubert avait une intention en laissant ce premier chapitre à la première personne, on ne voit pas bien laquelle, et lui-même, qui pourtant ne détestait pas révéler ses secrets d'atelier, ne s'en est pas expliqué. À nous autres modernes, cela fait un effet bizarre, donc séduisant, mais Flaubert ne visait pas ce genre d'effet, et ce qui me semble tout compte fait plus plausible, c'est qu'à force de se focaliser sur des détails minuscules il n'ait, comme un presbyte, pas repéré au fil de ses centaines de relectures ce vestige d'un premier jet depuis longtemps abandonné. Il se voit comme le nez au milieu de la figure, le premier mot du livre est ce nous qui s'effacera comme les dinosaures se sont effacés de la surface de la Terre, mais justement, il se voit tellement, et Flaubert a dû tant le regarder que peut-être il a cessé de le voir. (2018b: 442)

Como la carta robada de Poe, invisible por estar a la vista de todos, a fuerza de repasar el más nimio detalle de su libro, Flaubert habría dejado de fijarse en lo más evidente, en la primera palabra. Tengo en gran estima las atrevidas paradojas que Carrère acostumbra a servir a sus lectores, pero en esta ocasión confieso que no logro seguirle, y, a juzgar por los modalizadores de su argumentación, sospecho que tampoco él tenía muchas ganas de continuar por un camino tan aventurado, tan pocas que en última instancia optó por sacrificar toda la digresión, suprimiéndola de la versión final de Le Royaume.

No negaré que incluso un escritor tan meticuloso como Flaubert pueda cometer errores, pero no parece demasiado plausible que lo haga al comienzo de su novela, un lugar particularmente sensible, como el propio Carrère sabe mejor que nadie, por constituir la puerta de entrada al universo ficticio, por ser el lugar donde se inicia al lector en los usos del texto, y donde por tanto menos oportuno resulta equivocarse y más necesario estar vigilante. Además, no es la única ocasión en que Flaubert inicia uno de sus relatos con una irregularidad: por ejemplo, en el tercer párrafo de Un coeur simple emplea un pronombre de tercera persona «elle» que a simple vista podría remitir tanto a Félicité como a su ama. Esta ambigüedad referencial, este equívoco, no es sino la prefiguración de una escena crucial del cuento en la que, a pesar de la distancia social, ambas mujeres se (con)funden en un abrazo. Y en la primera frase de Bowvard et Pécuchet es tal el cúmulo de contrasentidos y de 
redundancias en tan pocas palabras que el lector avezado no necesita esperar a que aparezcan los dos graciosos protagonistas para soltar una carcajada. Semejante propensión a comenzar con alguna anomalía por parte de un autor tan puntilloso y que soñaba con escribir textos arreglados «de telle manière que le lecteur ne sache pas si on se fout de lui, oui ou non» (Flaubert,1973: 679), es decir textos de sentido indecidible -por retomar un término grato al propio Carrère-, no puede más que resultar sospechosa.

Por otra parte, invalidar la posibilidad de que se trate de un artificio voluntario porque Flaubert no alude a este pronombre en su correspondencia no parece un argumento muy sólido. Nada dice tampoco el novelista del «eterno imperfecto» que caracteriza su prosa y que Proust encontraba tan innovador, ni de su mayor aportación técnica a la literatura: el estilo indirecto libre. Como tampoco comentó nada del «passé défini, du passé indéfini, du participe présent, de certains pronoms et de certaines prépositions», gracias a cuyo original empleo había renovado Flaubert «presque autant notre vision des choses que Kant, avec ses Catégories, les théories de la Connaissance et de la Réalité du monde extérieur.» (Proust, 1987: 63) No, Flaubert no habla nunca en sus cartas de tales tiempos verbales y pronombres, pero no por eso dejó de hacer un uso deliberado, artístico y novedoso, de ellos.

Por último, que se desconozca la intención de Flaubert al mantener en las páginas iniciales la primera persona no prueba nada, antes bien podría invitar a pensar que este comienzo es en realidad un lugar menos común de lo que aparenta, particularmente intrincado y tal vez gobernado por la simulación. Así lo sugiere desde el primer párrafo el hecho de que cada cual se levante «comme surpris dans son travail». Además, basta observar al «nous» y la escena que lo envuelve con la misma atención que éste pone en describir la famosa gorra del recién llegado, para darse cuenta de que esta entrada en materia, en apariencia soporífera y estereotipada como un ejercicio escolar-Describa la entrada de un nuevo alumno en clase- es una de las más complejas, ricas y artificiosas que pueda imaginarse.

$\mathrm{El}$ «nous» de Madame Bovary es el caballo de batalla de los especialistas de Flaubert. Hace unos veinte años recopilé en La scène originaire de Madame Bovary más de cincuenta estudios relevantes dedicados a analizar el papel y el significado de este pronombre. Desde entonces han seguido apareciendo trabajos esclarecedores al respecto, como Le vean de Flaubert de Alain Vaillant (2013), de modo que ahora disponemos de una información muy consistente sobre este inicio. Emmanuel Carrère difícilmente podía tener noticia de estos trabajos especializados, casi todos universitarios, pero en la actualidad parece más plausible considerar la desaparición del «nous» del Estudio como un artificio, como un error estudiado, 
que como un verdadero despiste. Todo un juego de similitudes pone de manifiesto esta intencionalidad: este pronombre primordial no es lo único que se esfuma en estos primeros compases de la novela, pues, la extravagante y variopinta gorra del «nouveau»-otra singularidad plural- corre la misma suerte, desaparece para siempre mientras su propietario se desgañita para decir su nombre, sin que lleguemos a saber nunca quién se la sustrajo ni adónde fue a parar. La gorra es una monstruosidad descriptiva como el «nous» es una aberración narrativa, emblemas parejos asimismo de una escena inicial que los contiene y que desaparece a su vez de nuestra memoria en cuanto la historia se centra en su auténtica heroína. Ni en el tono ni en la temática cuadra esta escena escolar con el resto de la novela, como una cabeza que no casa con el resto del cuerpo, y resulta natural que la olvidemos sin tardanza. Tan es así que en ninguna de las numerosas versiones cinematográficas de Madame Bovary figura la entrada de Charles Bovary en el estudio. Pero si resulta prescindible para la trama, en cambio es indispensable para su composición, porque todo en esta novela emana de ella, como una sonata de su exposición: temas, motivos y fórmulas verbales presentados al principio juegan luego entre sí dando lugar a nuevas figuras. En realidad, tampoco la gorra ha desaparecido de verdad, sólo está escondida en el resto del texto para resurgir, apenas disfrazada, en un nuevo avatar, por ejemplo, en la no menos grotesca tarta de bodas de Charles y Emma. Y como cabía esperar en consecuencia, tampoco se ha volatizado del todo el narrador-testigo anónimo y misterioso del inicio, más bien ha mudado de apariencia, pero sigue presente a lo largo de toda la novela, como un dios oculto, como un demiurgo malicioso: lo reconocemos en el uso ambiguo y constante del «on»; en los varios «nous» universales de frases maximalistas que implican la existencia de un narrador personal no mucho más vago que el inicial; en el estilo indirecto libre, donde los enunciados de un personaje se insertan en la voz del narrador constituyendo a su vez una suerte de nosotros indefinido; o en la impactante aparición del presente de indicativo de la última frase de la novela -«Il vient de recevoir la croix d'honneur» (Flaubert,1994: 529) - que certifica que el narrador homodiegético sigue ahí. Más allá de las apariencias, el «nous» está presente de principio a fin, como alfa y omega que es.

El principio de Madame Bovary es un relato originario y de los orígenes. Como en las capas superpuestas de la gorra, en la escena inicial están engastadas varias figuraciones del origen: figuración del nacimiento y bautizo del protagonista a través de un rito de paso, figuración del aprendizaje de la escritura (estamos en el estudio, donde se aprende a leer y escribir) y figuración de la aparición de un nuevo escritor de estilo novedoso. Pero esta escena 
iniciática es también originaria, generadora, porque a través de un dispositivo propio tanto de la poesía como del chiste, nace la novela. Sabido es que Flaubert era muy aficionado a los juegos de palabras, a los calembours, tanto que, al modo de los pintores primitivos, se retrató a sí mismo en Madame Bovary bajo la apariencia de un artista llamado Vaufrylard, «qui, tout le temps, débita des calembours» (1994: 524). Este apellido, con el que el novelista normando se presentaba en los salones de Madame Sabatier, era ya uno de sus típicos juegos de palabras: Veau frit lard, un becerro que fríe tocino. No otro es el artificio que gobierna la creación de la primera escena de su novela, provocando en el «nous» una ola de carcajadas. Y este procedimiento no sólo se sirve de la lengua francesa, sino que también descansa, como la enseñanza de la época, sobre las lenguas clásicas, pues estamos en el Estudio, donde el profesor detiene la algarabía general con el amenazante y divino Quos ego y donde ordena al nuevo copiar veinte veces el verbo Ridiculus sum. En primera persona del singular, pero también del plural. En todas sus formas.

Para apreciar este procedimiento rousseliano avant la lettre un ejemplo bastará: el «nous», palabra primigenia de la novela, precede y genera fonéticamente al «nouveau» en la primera frase manifiestamente aliterativa. Por gemación celular, el «nou-veau» se convierte en un «veau», en un becerro que se comporta como tal, es decir, en francés, como alguien falto de energía y estúpido. Pero, para su desgracia y la de su esposa en el futuro, el toro potencial que es pierde de golpe todos sus atributos - la abigarrada y desmesurada gorra itifálica que en vano trata de mantener sobre sus rodillas-, de modo que, como Emma comprobará la noche de bodas, el novillo se queda en simple buey, en un bouf(del latín, bos, bovis), en ese Charbovari al que él mismo priva de la simbólica l cuando berrea su nombre, para alegría de todos los demás. Con estos mimbres, la vida de Charles y Emma estaba condenada a ser una lamentable historia de cuernos. No le faltará razón a Charles Bovary cuando al término de la novela, convertido ya el bouf en veuf, diga con inesperada lucidez que todo era culpa de la Fatalidad. En sentido exacto y literal. Al pie de la letra.

Visto así, Madame Bovary es una novela disparatada y delirante. Sostenía Roland Barthes que, a pesar de su perfecta legibilidad, el discurso de Flaubert era bajo cuerda uno de los más locos que pudiera imaginarse: «la narrativité est déconstruite et l'histoire reste cependant lisible.» (2002: 223) Ahora bien, Flaubert tuvo fugazmente la tentación de enseñar lo que escondía debajo de la alfombra. En un epílogo que acabó descartando, quiso retratar a Homais contemplándose en un espejo. Pero la satisfacción inicial por admirar su Cruz de Honor dejaba paso de repente a una crisis metafísica y, al verse reflejado, dudaba de su 
existencia, llegando a preguntarse si no sería «un personnage de roman, le fruit d'une imagination en délire» (Ms g9 $\mathrm{F}^{\circ} 39$ r ). No le faltaba razón a este farmacéutico, pero de haber conservado su autor este pasaje nivolesco, esta duda existencial habría proyectado una nueva luz sobre la novela y su «nous». Porque Homais no hace más que retomar la frase que en la versión definitiva de La tentation de saint Antoine había puesto Flaubert en boca de Valentín el Gnóstico, justo antes de que éste expusiera al ermitaño su cosmogonía: «Le monde est l'oeuvre d'un Dieu en délire.» (1964: 536) El artista debe ser como Dios en su creación, decía Flaubert, pero el dios que gobierna el universo de Madame Bovary más parece demiurgo que Dios supremo. El Romanticismo fue un renacimiento gnóstico, como bien ha explicado Gusdorf (1993: 512), y, como viejo romántico que era, Flaubert siempre sintió gran atracción por estas religiones que explicaban el mal por haber sido creado el mundo por un dios imperfecto que no era más que una lejana emanación del Dios auténtico. Goethe, Blake, Novalis, Nerval y tantos otros poetas vieron en el demiurgo gnóstico una imagen del propio artista. En las tres versiones de La tentation de saint Antoine que Flaubert escribió a lo largo de su vida, hizo que los herejes gnósticos abrumaran a Antonio con la exposición de sus doctrinas. Muchos fueron los tratados que leyó y reprodujo Flaubert con este fin. Su fuente principal a este respecto fue el libro de Jacques Matter, Histoire critique du gnosticisme, donde leyó que según Valentín el «Nous est la permière manifestation des puissances de Dieu, le premier des Éons, le commencement de toutes choses ; c'est par lui que se révèle la divinité.» (1844: 55) El propio Flaubert, tanto en la versión de 1849 de La tentation de saint Antoine como en la de 1856, puso en boca de Simón el Mago que Ennoïa «était la pensée du Père, le Nous indestructible qui créa les mondes.» (1964: 395 y 482). Para los gnósticos, en el principio no era el Verbo, era el Nous. El «nous» que da comienzo a Madame Bovary, ente nebuloso como un espíritu, unidad primordial y principio gracias al cual el universo novelesco emerge de la nada y se engendra a sí mismo emanación tras emanación (nous-nouveau), no es más que un avatar del Nous indestructible. Él es el principio que rige la novela, el dispositivo diabólico y lúdico que todo lo pone en marcha.

Lector perspicaz donde los haya, Baudelaire quiso en la apasionada reseña que dedicó a Madame Bovary establecer un paralelismo entre esta novela y los pocos fragmentos que se acababan asimismo de publicar de La tentation de saint Antoine. En esta obra, decía el poeta, Flaubert no se había disfrazado como había hecho en su Bovary, pero en realidad Emma estaba igualmente «tentée par tous les démons de l'illusion, de l'hérésie, par toutes les lubricités de la matière environnante.»(1954:1012) Dios había abandonado ese mundo 
ficticio edénico, al igual que Yanoda, el médico al que sustituyó Charles Bovary, se había fugado de Yonville. (1994:186); Yanoda al que el espejo de Homais le habría devuelto su verdadera imagen: Adonaï, el Creador. Tal parece como si la obra a la que Flaubert había terminado renunciando a su pesar y de la que no dejaba de hablar mientras escribía Madame Bovary, se hubiese vaciado en esta novela. En la primera escena -lugar que viene a ser un remedo y una derivación del Génesis, en palabras de Grivel (1973: 90)-, Flaubert reproduce veladamente el origen del universo gnóstico que parecía haber desertado. Y de esta génesis emana la totalidad de una novela concebida como si fuera el reverso diabólico de la propia Biblia.

En La scène originaire de Madame Bovary examiné en detalle el sustrato religioso sobre el que se asentaba de principio a fin la novela, pero al término de mi indagación no estaba del todo satisfecho. Si bien el «nous» parecía efectivamente desempeñar en el universo novelesco de Madame Bovary un papel análogo al Nous gnóstico, su singular comportamiento me hacía sospechar que tenía su origen también en algún modelo narrativo religioso, pero no encontraba ningún ejemplo que se le asemejara. Así que cuando años más tarde leí el artículo de Carrère, en el que ponía en paralelo el «nosotros» de Lucas -ese evangelista que tiene al buey como símbolo- y el «nosotros» de Flaubert, me entusiasmé pensando que bien podía ser éste el prototipo que tanto había buscado. Sin embargo, tras la euforia inicial surgieron las dudas.

A pesar de que hubiera terminado escribiendo tres cuentos donde lo cotidiano y lo sacro se entremezclaban, de los cuales el último era una reescritura de la historia evangélica de Juan Bautista, no era seguro que Flaubert hubiese leído los Hechos de los Apóstoles. Pronto comprobé sin embargo que conocía muy bien este texto, tanto que en el primer capítulo de La tentation de saint Antoine de 1874, para intentar espantar la nostalgia que le hacía recordar una Alejandría plagada de sectarios de Valentín y otros gnósticos cuyos discursos le volvían a veces a la memoria, el anacoreta decidía refugiarse en la Biblia abriendo precisamente en primer lugar los Hechos de los Apóstoles: «Si je prenais... la vie des apôtres?... oui!.. N'importe où!» (Flaubert, 1964: 525). Lo que le depara la suerte al hambriento ermitaño es el pasaje donde Dios le envía a Pedro animales vivos para que los mate y coma (Hechos, 10:11). También la Biblia puede ser fuente de tentaciones.

Que Flaubert conocía los Hechos, vista la ingente cantidad de lecturas religiosas que había hecho a lo largo de su vida, caía ya dentro de lo previsible, pero esto no significaba necesariamente que hubiera prestado atención al singular «nosotros» de Lucas. Además, tal 
vez nadie reparaba entonces en estas cosas. En realidad, sí. En Les apôtres, en un pasaje que parafraseó Carrère, el propio Renan le dedica a este «nous» cinco páginas en las que trata de averiguar la identidad del autor de los Hechos. Tan narratológico es su análisis que podría tomarse por un estudio contemporáneo del «nous» de Madame Bovary: «L'emploi du "nous" commence au moment où Paul passe en Macédoine pour la première fois (xvi, 10). Il cesse au moment où Paul sort de Philippes. Il recommence au moment où Paul, visitant la Macédoine pour la dernière fois, passe encore par Philippes (xx, 5, 6). Dès lors, le narrateur ne se sépare plus de Paul jusqu'à la fin.»(1866: XII) Renan había estudiado a fondo la cuestión, pero Flaubert no pudo basarse en sus observaciones, porque cuando el historiador publicó Les apôtres hacía ya diez años que el novelista había escrito Madame Bovary.

Puede, sin embargo, que Renan nos ponga sobre la pista. A pesar de la amistad que les unía y del éxito que había cosechado con La vie de Jésus, a Flaubert no le había gustado demasiado este libro, al que le reprochaba su poca profundidad; prefería un estudio homónimo anterior, que incluso le había recomendado en su lugar a Mlle Leroyer de Chantepie en octubre de 1863: «Connaissez-vous La Vie de Jésus du docteur Strauss? Voilà qui donne à penser et qui est substantiel! Je vous conseille cette lecture aride, mais intéressante au plus haut degré.» (Flaubert,1991: 352) No era una lectura reciente, pues Flaubert conocía bien este libro que había leído con pasión durante la redacción de la primera Tentation de saint Antoine, tal como entonces, en 1847, se lo había dicho a Louise Colet (Flaubert,1973: 466). Este sesudo estudio, que seguía vivo en la memoria de Flaubert tantos años después, es ciertamente muy interesante, especialmente para el caso presente, porque en sus páginas el historiador alemán ya se había ocupado del «nous»: «le rédacteur des Actes des Apôtres dans quelques chapitres de la seconde moitié (16, 10-17; 20, 5-15, 21, 1-17; 27 , 1-28, 16) parle de lui et de l'apôtre Paul à la première personne du pluriel (nous avons cherché, nous avons été appelés); par conséquent il se donne comme compagnon.» (Strauss,1839: 74-75) Pero lo que extrañaba a Strauss de este «nous» que aparece y desaparece como los ojos del Guadiana, es que el narrador no indicara su relación con Pablo, condenándose así al anonimato, y teniendo por tanto el investigador que conjeturar que estos pasajes del «nous» eran inserciones de otro autor. Sea como fuere, en este libro bien pudo advertir Flaubert la existencia de este peculiar pronombre del Nouveau Testament, si es que no lo conocía ya, y años más tarde inspirarse en él, consciente o inconscientemente, para escribir su escena primordial, bíblica y herética a un tiempo, que empezaba con otro «nous» no menos 
misterioso. No debería por lo tanto sorprender que el «nosotros» de los Hechos evocara para Carrère el de Madame Bovary.

La literatura sagrada nunca cesa de impregnar con su lenguaje y sus símbolos la literatura profana. Flaubert escribió una novela saturada de elementos religiosos y sustanciada en una cosmogonía que habían resucitado los poetas de su juventud. Por su parte, Emmanuel Carrère, además de invitarnos en Le Royaume a leer los textos bíblicos como si fueran profanos, encuentra en ellos la inspiración para su literatura inquisitiva. Él mismo confiesa que se retrató bajo los rasgos de Lucas y que «comme Flaubert de Madame Bovary je pourrais dire : “Luc, c'est moi”.» (Carrère, 2016: 51) Pero no fue el único evangelista al que su escritura se adhirió, pues en 1995 tradujo en tándem con un experto el Evangelio de Marcos. Muchas fueron las dudas que le asaltaron a la hora de traducir este texto, pero al final optó por plegarse a la singularidad del original y reproducir fielmente la expresión apagada y entrecortada del evangelista. Esto significó renunciar a su propio estilo, a esas características frases suyas, enlazadas unas con otras con total fluidez, aunque al hacerlo encontró por añadidura el tono que necesitaba para escribir en primera persona el libro que iba a cambiarle la vida: «Cette traduction m'a aidé à trouver le ton de L'Adversaire.» (2014: 548). Con esta obra se apartó de la famosa impersonalidad flaubertiana, pero nunca acabó de olvidarse de ese «nous» irregular que desde el inicio la cuestionaba. En este «nous», como en el de Lucas, buscó sin saberlo una voz propia que no fuera egocéntrica, que le permitiera aproximarse a los demás, a las vidas ajenas, y ser así un auténtico testigo. Pero no advirtió ni sospechó que ambos pronombres pudieran estar ligados, que el narrador de la historia de los Bovary y Lucas el Buey pudieran tener algún parentesco entre sí. La solución estaba sin embargo a la vista, como la nariz en plena cara - por retomar su expresión-, estaba inscrita en su propio nombre y por tanto en el de la señora Bovary: Emma, Emmanuel, 'E $\mu \mu \alpha$ voùं $\lambda$, Emmanouēl, ese nombre con el que se designa al Mesías y que significa en hebreo, como sabe mejor que nadie Emmanuel Carrère, «Dios con nosotros». 


\section{BIBLIOGRAFIA}

Baudelaire, Charles (1954): Euvres complètes, edición de Y.G. Le Dantec, Paris, «Bibliothèque de la Pléiade», Gallimard.

Carrère, Emmanuel (1986): Le Détroit de Behring, Paris, P.O.L Éditeur.

Carrère, Emmanuel (2000): L'Adversaire, Paris, P.O.L Éditeur.

Carrère, Emmanuel (2014): Le Royaume, Paris, P.O.L Éditeur.

Carrère, Emmanuel (2016): Il est avantageux d'avoir où aller, Paris, P.O.L Éditeur:117-133.

Carrère, Emmanuel (2018a): «L'écrivain, les assassins et la petite dame au fond de la province.

Discours de réception du Prx FIL (Foire Internationale du Livre)», en Laurent Demanze \& Dominique Rabaté (eds.) (2018) : Emmanuel Carrère. Faire effraction dans le réel, Paris, P.O.L Éditeur:530-537.

Carrère, Emmanuel (2018b): «La première personne», en Laurent Demanze \& Dominique Rabaté (eds.) (2018b): Emmanuel Carrère. Faire effraction dans le réel, Paris, P.O.L Éditeur: 440-443.

Demanze, Laurent (2014): «Une façon de vivre: entretien avec Emmanuel Carrère», Roman 20-50, 57: 15-22.

Flaubert, Gustave (1964): Cuvres complètes, I, Paris, Éditions du Seuil.

Flaubert, Gustave (1973): Correspondance, I, edición de Jean Bruneau, Paris, «Bibliothèque de la Pléiade», Gallimard.

Flaubert, Gustave (1991): Correspondance, III, edición de Jean Bruneau, Paris, «Bibliothèque de la Pléiade», Gallimard.

Flaubert, Gustave (1994): Madame Bovary, edición de Pierre-Marc de Biasi, Paris, Éditions Imprimerie Nationale.

Flaubert, Gustave (2002): L’Éducation sentimentale, edición de Pierre-Marc de Biasi, Librairie Générale Française.

González, Francisco (1999): La scène originaire de Madame Bovary, Oviedo, Servicio de Publicaciones de la Universidad de Oviedo.

Grivel, Charles (1973): La production de l'intérêt romanesque, The Hague, Mouton.

Gusdorf, Georges (1993): Le romantisme I. Le savoir romantique, Paris, Payot \& Rivages.

Jablonka, Ivan (2014): L'bistoire est une littérature contemporaine. Manifeste pour les sciences sociales, Paris, Éditions du Seuil. 
Kapuściński, Ryszard (2006): Viajes con Heródoto, traducción al español de Agata Ozeszek, Barcelona, Editorial Anagrama.

Martínez, Patricia (2019): «Poétique de la fiction: le discours métalittéraire dans les récits d'Emmanuel Carrère», en Relief, 13, 2: 45-62.

Matter, Jacques (1844), Histoire critique du gnosticisme, I, Strasbourg-Paris, Levrault.

Núñez Ramos, Rafael (2010): El pensamiento narrativo. Aspectos cognitivos del relato, Oviedo, Ediciones de la Universidad de Oviedo.

Otchakovsky-Laurens, Paul (2018): «L'amitié par le livre», en Laurent Demanze \& Dominique Rabaté (eds.) (2018) : Emmanuel Carrère. Faire effraction dans le réel, Paris, P.O.L Éditeur: 199-201.

Proust, Marcel (1987), Sur Baudelaire, Flaubert et Morand, Compagnon, Antoine (ed.), Bruxelles, Éditions Complexe.

Renan, Ernest (1866): Les apôtres, Paris, Michel Lévy.

Strauss, David (1839): Vie de Jésus, I, traduction de E. Littré, Paris, Librairie de Ladrange. Vaillant, Alain (2013): Le veau de Flaubert, Paris, Hermann. 
SOBRE EL AUTOR

\section{Francisco González Fernández}

Catedrático de literatura francesa en la Universidad de Oviedo.

Contact information: correo electrónico: frangon@uniovi.es 